\title{
Clinics and Hospitals
}

National Cancer Institute

\section{Source}

National Cancer Institute. Clinics and Hospitals. NCI Thesaurus. Code C19326.

Institutions with an organized medical staff for the medical care, treatment, and cure of the sick and wounded, for the study of disease, and for the training of physicians, nurses, and allied health personnel. 